\title{
New tools for an integrated vision of the territory: "LANDSCAPP"
}

\author{
Francesca Romana Lugeri $\circledast^{1,2 *}$, Piero Farabollini $\odot^{1}$, Nicola Lugeri ${ }^{2}$ \\ ${ }^{1}$ School of Science and Technology, University of Camerino, Italy, *francesca.lugeri@unicam.it \\ ${ }^{2}$ ISPRA Institute for Environmental Protection and Research, Roma, Italy
}

\begin{abstract}
Landscape is part of everyone's cultural heritage, if recognized and understood; such consciousness fosters a more creative participation of society in a balanced management of the territory and sustainable development: an important resource in times of crisis. Cognitive tools now enjoy a wide use and offer us a means of immediate communicative diffusion of scientific knowledge relative to an area and an environment. LANDSCApp, a smartphone app, gives the public a chance to try an alternative approach to the knowledge of the natural and cultural territorial heritage, thanks to a set of information related to the geological, morphological, environmental settings of the Italian landscapes.
\end{abstract}

Keywords: landscape, communication, geotourism, GIS, society

\section{Introduction}

We are living in the Anthropocene, term coined by Paul Jozef Crutzen, Nobel Prize for chemistry in 1995, to define the first geological era in which human activities have been able to influence the atmosphere and alter its balance (Crutzen 1995). The part of this era which we are living is characterized by technology and virtual reality, where all is superficial and fragmented as a broken mirror surface: we may call it postmodernity. A plethora of tools and sources offers everyone around the world the possibility of participating in social dynamics, a resulting side effect of which is an extreme superficiality and fragmentation of knowledge (Bauman 1997). Yet, more and more, socio-economic developments require a knowledge that keeps pace with the dizzying speed of technological evolution, which by now appears self-directed. The only possible solution is a shared awareness, and this can only be reached through knowledge, which is provided by science; at the same time it is essential a proper philosophy in sharing knowledge, in finding educational programs, in communicating.

Landscape is an object of human perceptions, therefore it could become a medium to communicate Earth Sciences to the whole society: it can be considered as the result of the interaction of many natural and cultural components, as well as the expression of the geological processes. Italy is a country that, thanks to its geomorphological configuration and its geographical position, offers an extraordinary richness of different landscapes; each one of these landscapes is the result of the physical, biotic, anthropic dynamics, interacting in space and time. The variety and the beauty of the Italian physiographic structure are, at the same time, signs of extreme vulnerability. The environmental problem is thus to be identified in the deterioration of landscapes of high environmental value and high vulnerability, that characterize our country, especially in tourism areas. Loss of landscape, loss of soil and loss of biodiversity: an equation, whose solution is exponential, whose effects are irremediable if we don't intervene promptly and appropriately (ISPRA 2018). Furthermore, it is worth underlining that the landscape loss has negative effects even on local and global cultures. The main causes of landscape's deterioration/loss are identified in the following crucial factors: climate change, anthropic pressure, lack of protection, lack of prevention, lack of education of the society. These factors are the result of the insufficient social awareness about what landscape is, about its importance for the life quality both of human beings and of the planet. Superficiality, lack of interest, indifference are consequences of the lack of knowledge. At a national 
level, there is a lot of information about these environmental issues, but it's not effective.

The aim of the project and its research style follow the International Year of Planet Earth (IYPE): a joint initiative by UNESCO and the International Union of Geological Sciences (IUGS). The IYPE aims to capture people's imagination with the exciting knowledge we possess about our planet, and to see that knowledge used to make the Earth a safer, healthier and wealthier place for our children and grandchildren. The IYPE aims to ensure greater and more effective use by society of the knowledge accumulated by the world's Earth scientists. The IYPE's ultimate goal of helping to build safer, healthier and wealthier societies around the globe is expressed in the Year's subtitle 'Earth science for Society' (IYPE 2007).

The diffusion of scientific heritage, using well known and appreciated topics, may represent one of the new goals for Territorial Sciences. From an examination of some of the dramatic events that have occurred in Italy related to the geo-environmental setting of the country and to the effects of the interaction with anthropic pressure, there emerges the need to provide the general public with correct and clear information on the complex scenario characterizing this - as well as another - country (Lugeri et al. 2018).

\section{The project in a glance}

LandscApp is part of a wider project focused on science's popularization, realized within a no cost cooperation between ISPRA - Institute for Environmental Protection and Research and the University of Camerino. The objectives that were identified are intended to strengthen the environmental knowledge, referring to landscape as a social common right, as well as a font of resources and of risks. This is the first step towards the environmental, seismic, geological risks prevention, thanks to the consciousness of the need of avoiding exposure to natural hazards. In parallel, further goals are focused on the mitigation of the damaging effects caused by natural events on the anthropic infrastructures, as well as on the promotion of landscapes' safeguard and enhancement, concretely avoiding further loss of landscape. The contemporary society needs to be sensitized on the urgent necessity to adopt virtuous behaviours for containing/ avoiding environmental risks and their effects, for the sustainable use of territorial resources, for promoting a process of democratic participation for a balanced landscapes' management and enhancement.

Basing on recent experiences, we can state that it is mandatory, in our country, to adopt a communication strategy of the Italian territory through the landscape, as a powerful instrument of the social recognition of a common heritage. The European Landscape
Convention (CEE 2000) provides legal and ethical references for the implementation of the present project's proposal. The first strategic objective is to communicate, reaching a wide and varied audience, in particular, those target groups that are less sensitized to environmental issues, while promoting intergenerational communication in order to involve the entire society. With the aim to reach such goals, we have experimented some tactics, based on new styles in communicating scientific topics to a wide audience. One of the most important component in our communicative project, is the surprise effect, reached by providing unexpected information through unconventional channels, using new technologies with low carbon footprint, balanced quality-costs and high didactic/ dissemination value. In other words, communication is inserted into appealing contexts, and the use of topics which are more attractive to the public as vectors of ecological concepts, is a successful step towards the purpose to connect society and environment (Lugeri et al. 2018). In this perspective, the so called outdoor sports, such as cycling, ski, sailing, trekking, become themselves vectors of information, giving the public a chance to observe the natural scenery of the sport performances, by a scientific point of view. An ace in the hole is the special guesting, thanks to the participation of leading figures, as popular testimonial (from the world of sport and show business).

All the foundations of the project create a field of actions, where it is possible to start new and creative activities of public information. The LandscApp, as described below, has been conceived in the spirit of giving the public a modern and friendly tool, useful to live, know, enjoy the Italian landscape in a better, conscious, sustainable way.

\section{Methodological approach: Landscape Ecology}

Ecology studies the relationships between living organisms and the surroundings environment, and the consequences of such relationships. The concept of ecosystem refers to a series of concepts from disciplines traditionally considered as distinct from each other (biology, ecology, geology, general systems theory, and thermodynamics). The term ecosystem integrates them and focuses the attention on the flow of energy, as a motor and expression of functional relationships between the components of an ecosystem (Amadio 2003). Ecology proposes a systemic approach to the study of the landscape, based on the integration between phenotypic structures and functional processes: the ecological approach is now considered the only way to guarantee a complete and detailed knowledge of the environment. 
The generic term of landscape indicates an intuitive notion deriving from the perception of a diversified physical environment. In this respect, it represents the visual manifestation of particular organizations of elements and structures (Forman, Godron 1986, Naveh, Lieberman 1994). Each individual landscape, studied at different scales, shows distinctive elements: structural, which depend on physical form and specific spatial organization; functional, which depend on relationships created between biotic and abiotic elements; dynamic, which depend on the successive evolution of the structure. In such terms, each landscape can be analysed culturally and scientifically in different ways and, in any case, can't be referred only to the complexity of the natural components (Forman, Godron 1986, Naveh, Lieberman 1994).

The study of landscape consists in a series of steps, but should be understood as a process whose phases, related to different disciplines, are integrated rather than simply in succession. As told before, the study of an area, performed following a holistic approach which integrates all the components of the studied area, is a one way road towards a complete understanding of the landscape. The holistic approach requires a different point of view compared to that of the specific disciplines, and it gets closer to the natural attitude to observation. In this sense, the study of the landscape contrasts with the fragmentation of knowledge: it requires a collective action, in which everyone is aware of putting his or her discipline in the service of a cognitive strategy. At the same time, an integrated interpretation of the landscape, offers new perspectives in the transmission of knowledge (Farabollini et al. 2014), while opening a dialogue between technicians, decision makers, politicians, citizens. Moreover, such vision offers an essential tool to those places more significant in terms of geodiversity, for their sustainable enhancement, for geo-tourism (Lugeri et al. 2012, Henriques, Brilha 2017, Zwoliński et al. 2018).

The methodology adopted in analysing the Italian territory takes into consideration all the components of landscape, and their dynamic interrelations, integrating the information according to the landscape ecology theories, which consider landscape as the result of interaction among physical, biological and anthropic phenomena acting in a different spatial-temporal scale (Forman, Godron, 1986).

\section{Materials and Tools}

Modern cartography, as a GIS product, is no longer just a descriptive representation of phenotypes: it is now enriched with ecological-functional meanings, becoming an interpretative tool of socio-ecological systems. In this sense, it is a ground-breaking discipline and has many different fields of application, such as spatial planning at different scales, environmental analyses, environmental impact assessment, nature conservation, sustainable development. The methodological approach aims to identify the criteria for analysis, evaluation, diagnosis and control of the systems of ecosystem, in which structure and function are integrated. A significant step forward is the possibility of developing indicators and models, scientific and technical tools suitable for a balanced land management.

Public participation geographic information systems (PPGIS) can be considered a natural evolution of GIS, as a tool in participatory democracy. The strong potential of such instrument is related to the multipurpose function, being made of different disciplines, different sectors, crossed and integrated thanks to appropriate GIS architectures (Sieber 2006, Lugeri et al. 2012, McKinster et al. 2013).

The Map of Italian Physiographic Units (Fig. 1), created at the 1:250,000 scale, identifies within the Italian territory 2155 areas, characterized by a homogeneous physiography, and by a characteristic geographic connotation as well. Each of these phys-

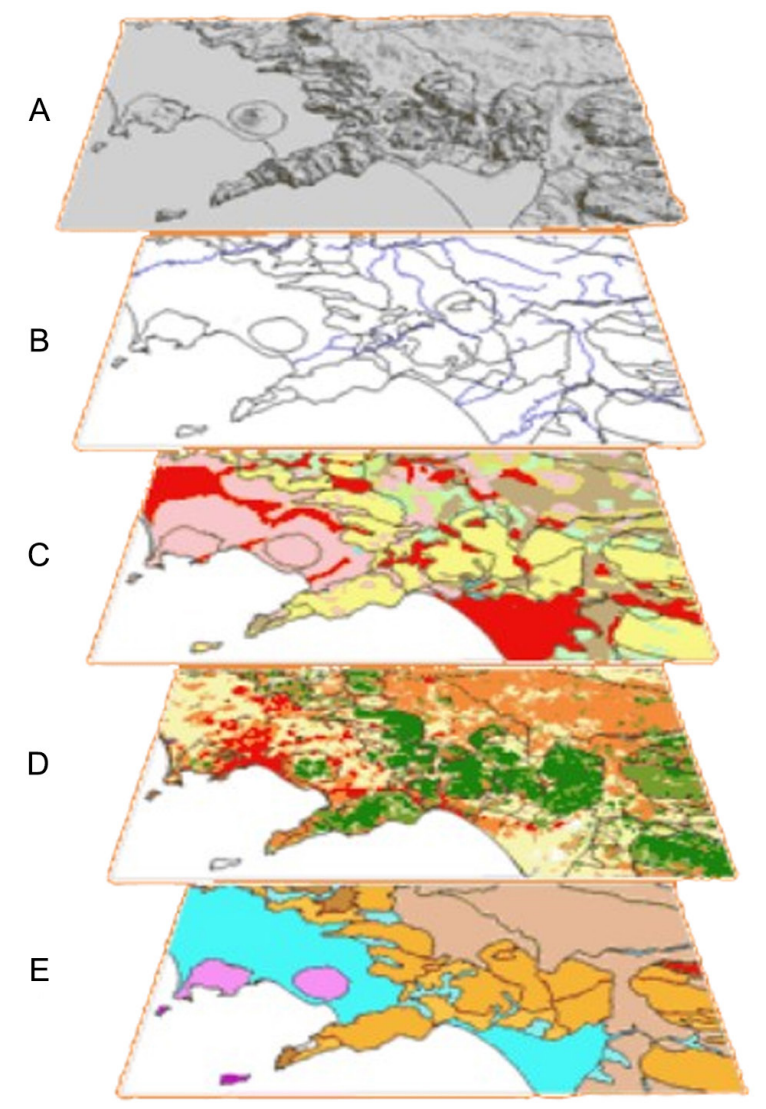

Fig. 1. A scheme of the layers integrated in the Physiographic Units Map, scale 1:250,000

A - altitude, B - characteristics of the hydrographic network, $\mathrm{C}$ - lithology, D - physical morphological components, E - land cover 
iographic units is classified referring to a list of 37 types of landscape, identified and reported at national level (Amadio et al. 2002). The physiographic units are described referring to some physical components, selected as emergent at the scale analysis, such as altitude and relief roughness, hydrographic network, lithology, physical morphological components, land cover (Fig. 1).

A database associated to the map integrates all the related data. These components, are considered in a systemic approach as a whole synthetic study object, which can be reinterpreted referring to structure, functions and dynamics, i.e. the key factors in defining an ecosystem (APAT 2004). The spatial arrangement of these characteristics allows us to identify the territorial pattern, where each patch of the mosaic is distinguishable from the surrounding ones; the so called Phisiographic Units are thus defined by typological properties, referred to the above described landscape approach, by following an inductive process. In parallel, the unit has a precise and univocal denotation, in relation to the geographical context in which it is located: such topological property is highlighted by following a deductive process (APAT 2003).

\section{Geomorpholandscapes}

Referring to the landscape analysis performed following the Carta della Natura 1:250,000 approach, it is possible to try an interpretation of territory in a dynamic sense, by monitoring landscape settings' evolutions in space and time. As preliminary step of the landscape analysis we refer to the concept of geomorpholandscape, conceived to address the need to synthetically describe the geological processes emerging at the landscape scale, allowing to link spatial patterns to geological processes. A geomorpholandscape is thus defined as a spatial object or component of a geological landscape, whose geo-morphological evolution, linked to the geological setting, are elements of aesthetical, semiological as well as historical and cultural value. (Farabollini et al. 2014). This concept derives from that of geomorphosite one, i.e. a geomorphologic landform with a scientific, cultural and socio-economical value (Panizza, Piacente 2005, Panizza, Reynard 2005). In our approach, we aim at highlighting how the structure of the landscape is represented by the physical shape and spatial organization, in a dynamic way. Each geoform has in itself geological, geomorphological, landmark, historical and cultural features, of such special relevance, that they can be defined in terms of scientific quality, rarity, aesthetic appeal and educational and cultural value. In parallel, it is necessary to supply a readout of the functions provided by the interaction of land- scape's components, in order to perform an integration the geomorphological, lithological, cultural, geodiversity data.

So, the physiographic unit are a denotative result of landscape analysis, graphically displayed as GIS map representation, showing the landforms in their reciprocal position; in parallel, the concept of geomorpholandscape is a connotative term, giving information about the reciprocal interaction and integration of the landscape components.

\section{LandscApp}

Modern cartography and GIS are the best tools to represent the significant link between nature and culture in the territory. The thematic maps obtained with GIS, provide the identification and representation of the landscape; at the same time, they represent a powerful means of communicating the territory to society.

LandscApp is an App for smartphone and tablets, realized at the moment in an experimental version as a web App ${ }^{1}$. It represents a social tool, useful to make the users understand the main geomorphological characteristics of an area, particularly referring to the touristic ones (Gambino et al. 2017). In the LandscApp, a 3D representation of the land is available, with different thematic maps draped over the Digital Terrain Model of the portions of territory, paying a special attention to the selection of the most up-todate and representative geological or geomorphological maps available. Starting from a collection of landscape pictures, as a basis for an integration with the thematic Maps, LandscApp provides the user with a landscape analysis tool, understandable and full of significance.

By selecting the area of interest, the user discovers the main reasons why, when and how the landscape he is observing/enjoying was and is evolving. A scientific description of the interested areas is available at different level of detail, selected directly by the user. LandscApp, developed as a web app, allows this new way to get information, thanks to the GIS that make available a friendly access to maps, 3D modelling, and related data base (Fig. 2).

This is obviously just one of the multiple proposals made up to give the public the possibility to know and better appreciate the geological heritage (Cayla 2014, Pica et al. 2017, Cayla, Martin 2018), LandscApp aims at inflecting the potential of the scientific communication via app or web app, in a different way: the most relevant difference is the audience it addresses. Our target is the public not yet interested

\footnotetext{
www.ost.sinanet.isprambiente.it/cortina
} 

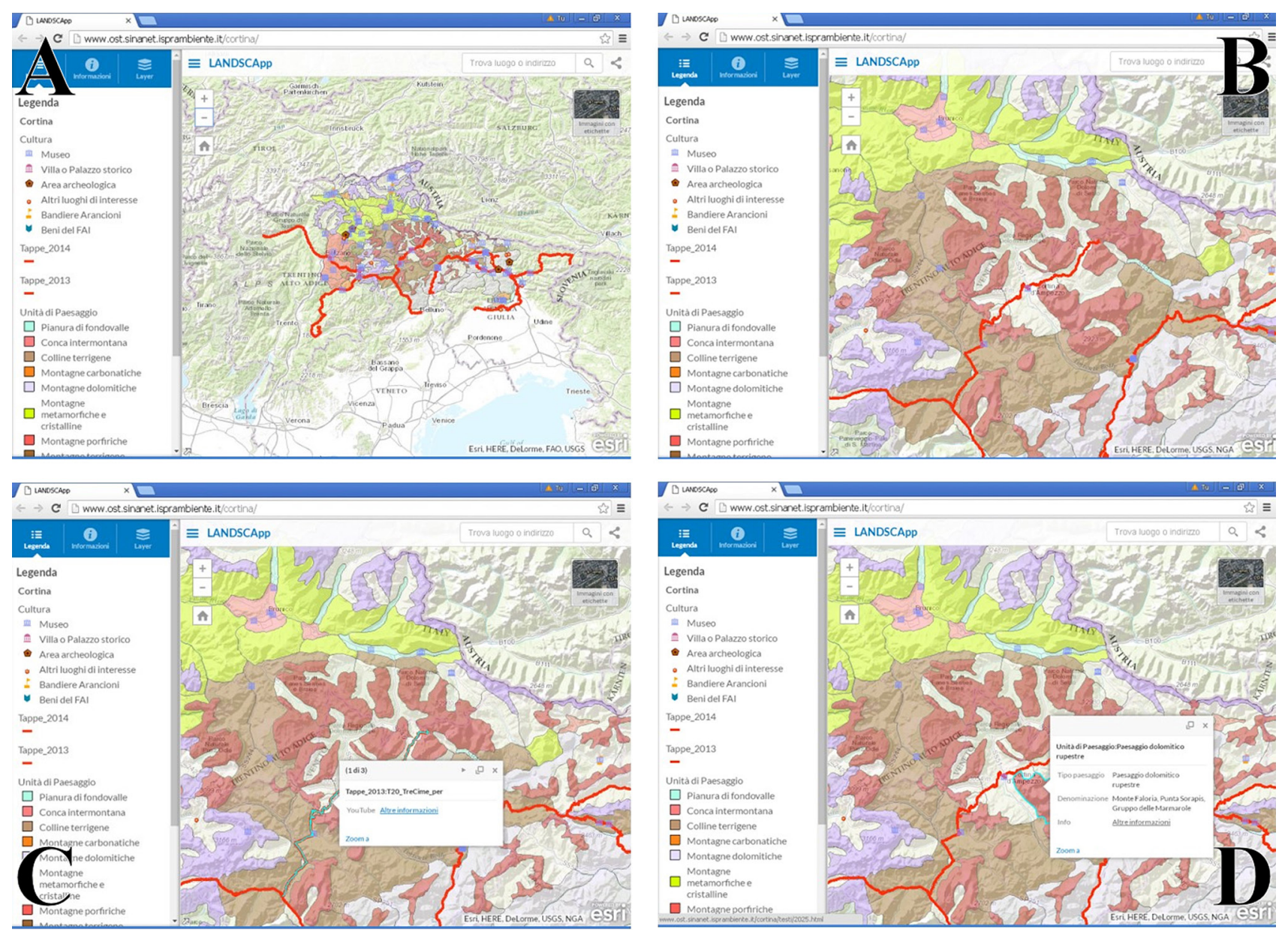

Fig. 2. Some screenshots from the LandscApp

The red lines represent the track of the Dolomitic stages of the Giro d'Italia 2016. From A to D, images and interactive information are available at increasing level of detail

in discovering geoheritage neither in getting scientific information; the use of the app is catalysed by other kinds of interest, such as tourism or sports.

A divulgation of the tool is planned during the next Giro d'Italia, the cycling race crossing the Italian territory that has already hosted the GeoloGiro, a short TV space devoted to divulgation of the geo-environmental characteristics of each stage (Lugeri et al. 2012, 2018). Such activities have been encouraged by the success of the project GeoloGiro, especially referring to the most recent audience data (Fig. 3).

The public interested in the cycling event, while surfing the main cycling websites, will be directed to the LandscApp. Similarly for the public interested in tourism, in general, and/or in oeno-gastronomy: thanks to a cooperation between National Bodies and Local Administrations, the municipalities' official websites will offer to the visitors a link to our App. A complete program of integrated activities, as explained below, has to be further developed (hoping in the needed financial resources: the whole project has been realized until now only on our own).

Creation of itineraries served by LanscApp, capable to provide unexpected information through in- novative technological channels, with low cost and low environmental impact. The quality of the provided information is based on scientific concepts, made comprehensible to citizens using a simple language, accessible for all, though scientifically correct. The landscapes influences the cultural history of the pilot places; those information, unusual and less known by

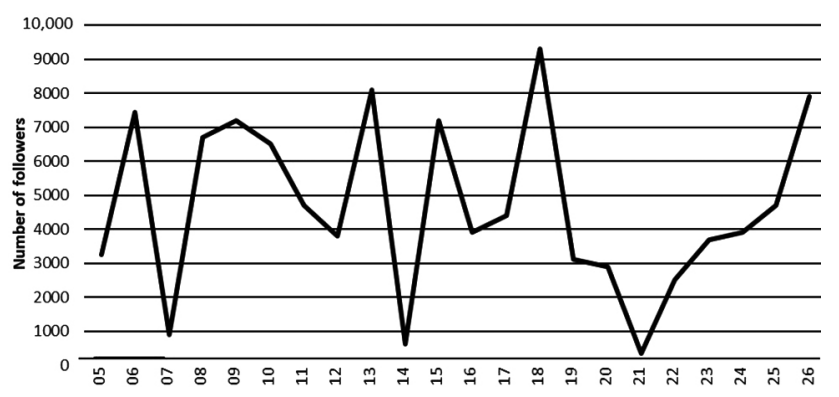

Fig. 3. Audience data of the "Repubblica delle Biciclette" a social media channel cooperating in the divulgative project GeoloGiro, referring to the geology and cycling events' followers, at the Calanchi bike marathon (May 6, 2018) and at the Giro d'Italia special interviews on the geological settings of the stages (May 8, 9, 10, 13, 15, 18, 26, 2018) 
the general public, will be linked to well-known and appreciated components of the Italian territory: biodiversity and local food products, geology and wine, lithology and architecture, natural environment and sports.

1. The itineraries will be inaugurated and illustrated to the wide audience within public events involving testimonials from the world of sports and show business. The importance of a testimonial is fundamental for reaching target groups not yet sensitized, by activating mechanisms of identification; this is an effective instrument, whose function is highlighted by social psychology.

2. Realization and dissemination of videos taken during the experiences, to be published on social media channels as well as on a dedicated website.

3. Realization of a fiction or web series devoted to tell the public stories about earthquakes, prevention, and reconstruction.

4. Realization of series of videos performed through the public participation in a docufilm style, in which the progress of the places affected by the project is shown, telling the story of the involvement.

All the actions/tools will be multilingual, in order to guarantee an international access and fruition.

The itineraries, identified among the most relevant and important places, will be accompanied by information, contained in LandscApp, on:

- landscape's general context,

- ecosystemic context of the place and surroundings,

- natural and cultural characteristics of every single place,

- local typical production of food and wine, their connections with the territory and its characteristics,

- invitation to visit further places, accompanied by the informative system.

\section{Pilot Places}

The choice of the following places has been guided by their relevance, the representativeness of the link between nature and culture, characterized by high environmental value and vulnerability. These places are distributed on the geographical context of the Italian peninsula, representing different environmental problems which are typical of the country. The locations have been chosen both for their physiographic structure, for the relation with society through time, and for the particular role they're going to assume in the next years.

Matera 2019, in the South of Italy, the city of Sassi (verbatim, Stones), historical homes of families and courtyard animals. Up to the 70's, it was the the shame of Italy; now, UNESCO World Heritage Site. Climate change and increasing anthropic pressure are menacing city landscape and its surroundings, in particular ravines, badlands areas (calanchi) and coastline. In 2019 Matera (along with Plovdiv, Bulgaria) will be the European Capital of Culture.

This pilot itinerary will be articulated among the Stones and the city's historical buildings; then it will continue in the badlands areas of Montalbano Jonico and Pisticci, in the surroundings of Matera, until it reaches the coastline, between the mouths of the river Bradano and the river Basento. These are precious biodiversity oasis, site of antique cultures (Metaponto), threatened by the phenomena of coastline erosion and marine litter.

Cortina 2021: Cortina, the pearl of the Dolomites: it's the symbol of the difficult coexistence between society and mountain environment, characterized by old - but still applicable - social rules for territorial management (Les Regles). It's been recently subjected to the effects of exceptionally intense weather phenomena, with landslides that deeply modified landscape (with the collapse of one the famous Five Towers). It will be the site, in 2021, of the World Ski Championship.

The itineraries will be targeted to summer and winter fruition. Summer itineraries will deal with trekking, with a specific attention to the so-called peace trails, recently created on the sites where the 1st World War was fought. For the winter itinerary, the focus will be on ski, referring to the tracks where athletes will compete for the Ski World Championship.

\section{Case studies}

As mentioned above, the choice of the places where to start the LandscApp experience (Figs 4 and 5), is based on their relevance in terms of environmental value and vulnerability as well as the particular role they're going to assume in the next years. Moreover, the geographical distribution in the Italian country, and the considerable difference of their environmental-geological context, gives us the chance to highlight the importance of the environmental diversity, intended as an integration between geodiversity and biodiversity.

\section{Italian Badlands}

Those places where clayey sands outcrop, with variable clay contents and low and diversified degrees of cementation, are characterized by numerous escarpments, mostly still active, corresponding to forms of selective erosion between layers with different degree of cementation. 


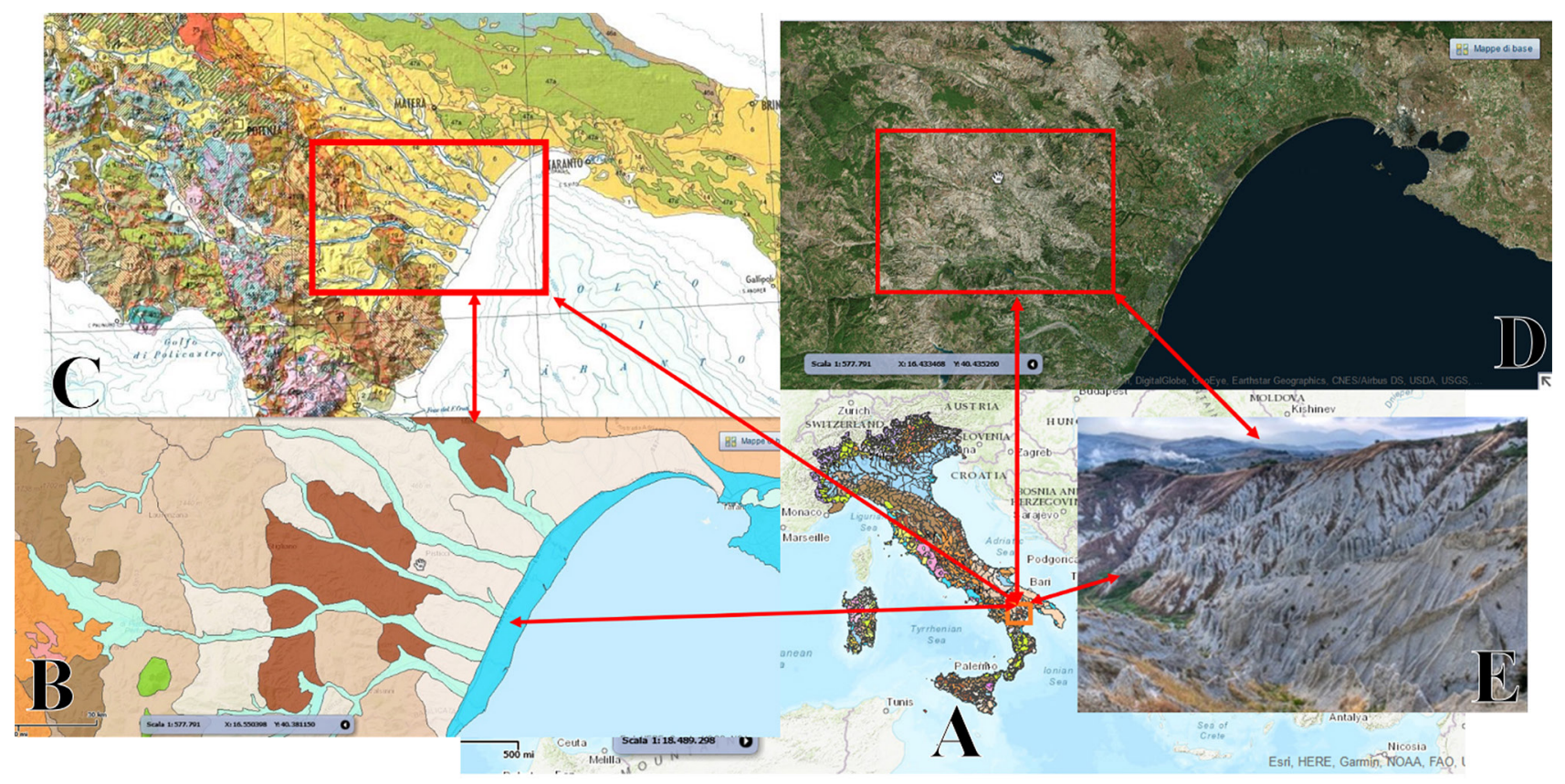

Fig. 4. A synthetic representation of the multiscale and multiphase approach used in studying landscape

A - Carta della Natura, physiographic units 1:250,000, in the box the case study: badlands in Basilicata region; B - the badlands physiographic unit in the terrigenous hilly landscape context; $\mathrm{C}$ - geologic map of the badlands' area; D - remote sensing image of the badlands' area; E - panoramic view of the badlands in Basilicata region (Montalbano Jonico)

Among the forms of erosion that characterize the so-called clayey landscapes, the badlands are perhaps the most spectacular ones (Farabollini, Miccadei 2009, Farabollini, Scalella 2014). Such landforms can be defined as drainage systems, developing very dense and hierarchical drainage networks, incised on steep clayey slopes and characterized by a dense alternation of furrows and ridges, narrow and sharp. The height is variable between a few meters and some decametres. The existence of clayey slopes, with marked steepness and lacking in vegetation, is an indispensable condition for the setting of the gullies. The slope's imperviousness and impermeability reduces water's infiltration into the ground and fa-

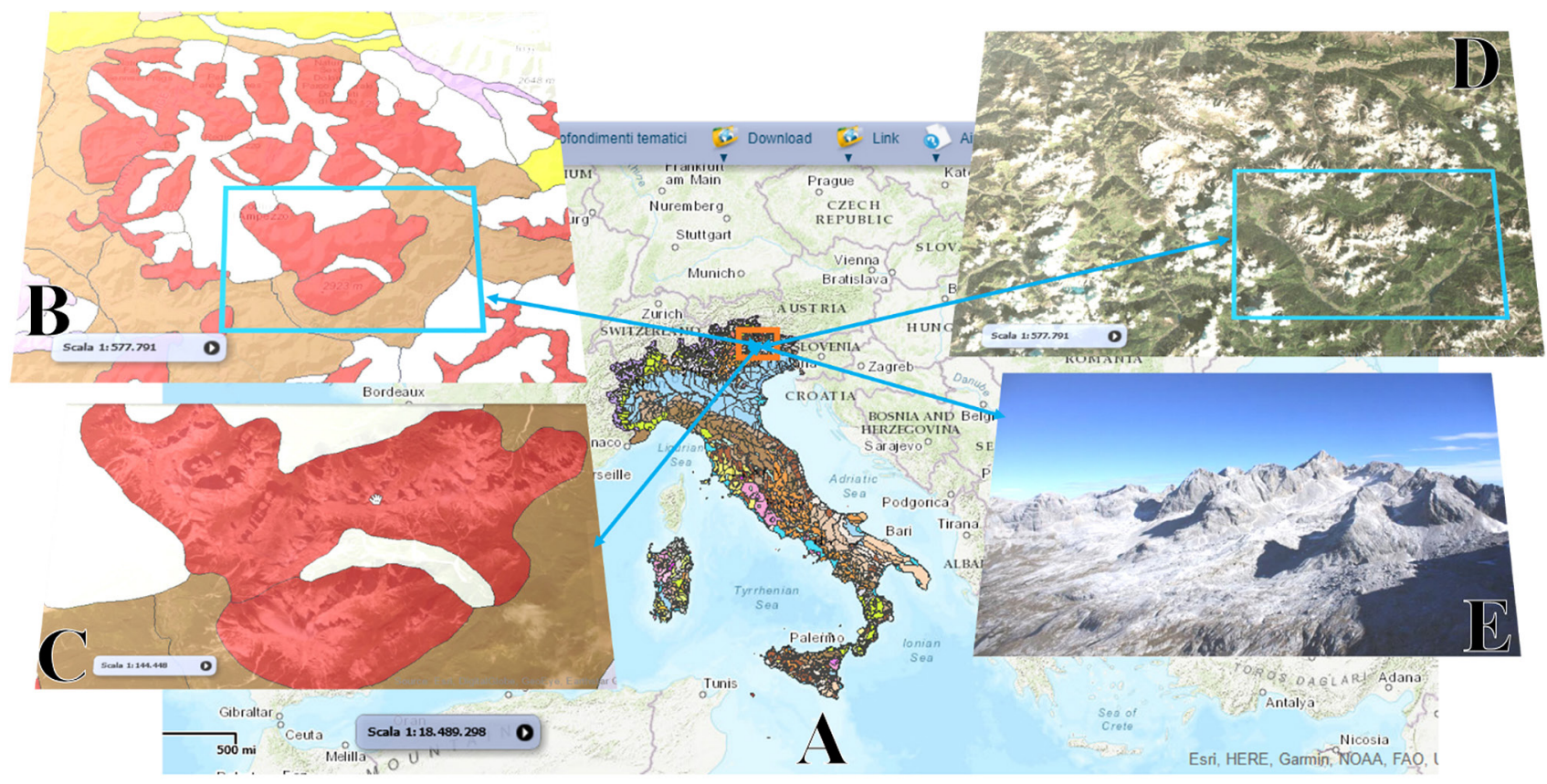

Fig. 5. A synthetic representation of the multiscale and multiphase approach used in studying landscape A - Carta della Natura, physiographic units 1:250,000, in the box the case study: Dolomiti, Marmarole Group; B - the Marmarole physiographic unit in the Dolomitic landscape context; C - a detail of the Marmarole physiographic unit; D - remote sensing image of the Marmarole Group; E - panoramic view of the Marmarole Group 
vours the fast surface runoff in rivulets (rills), and the incision of a dense drainage network. Its evolution can originate the badland form. The reduced infiltration also limits the importance of mass movements that would remove the superficial portions of the slope causing the obliteration of the badlands forms. The genesis of steep slopes can be connected with different processes, such as the rapid deepening of erosion due to tectonic or climatic causes, the direct action of dislocation's tectonics, mass movements and anthropic activity. Their possibility of persistence depends, however, on the lithostructural characteristics of the substrate and the degree of its superficial alteration (Dramis et al. 1982, Ciaranfi et al. 2010).

Climatic conditions strongly influence the geo-environmental settings; while in arid climate, the clayey slopes can remain steep for a long time for flat-parallel retreat, as the humidity increases the steepness decreases. The southern exposition, accentuating the arid conditions, may allow the slope to keep a higher inclination, thus favouring a greater presence of gullies on these sides, compared to those facing north. The different distribution of the gullies on the opposite valley sides is also due to the structural arrangement of the clays: the presence of anti-dip-slope layers favours a greater steepness of the slope and a greater persistence of these conditions, favourable to the badland morphogenesis; on the other hand, the dip-slope settings generally assume lower slopes, due to the stratification surfaces that favour conspicuous mass movements, producing a fast retreat of the slope and a lower steepness until an equilibrium value, compatible with that of the potentially sliding surfaces, is reached (Bentivenga et al. 1999, Festa et al. 2018). The mineralogical characteristics of the clays play an important role in the badlands morphogenesis: the presence of an abundant siltysandy skeleton making the clays more stable on steep slopes it is favourable to the formation of the calanchi; on the contrary, the content of a high fraction of expandable minerals such as montmorillonite, does not favour the badlands' morphologic settings. The anthropic activity, particularly the elimination of the vegetation cover, and the consequent denudation of the slopes, can significantly influence the badlands morphogenesis, favouring the accelerated erosion along the slopes. Last but not least, the lithological and structural characteristics of clay minerals, in addition to climatic conditions, control the genesis and distribution of the badlands forms, allowing the steepness of the slopes produced by different causes (D'Alessandro 2004). The Italian badlands generally show a good variety of types, characterized by distinct evolutionary conditions, in relation to the lithological and structural characteristics of the substrate, to local microclimatic situations, to the rates of deepening of vertical erosion. In many cases the badlands slopes evolve due to mass movements; in others the morphogenetic effects of surface running waters appear to be the essential factor; sometimes, especially in the case of northern exposure, we observe badlands forms almost completely obliterated by generalized mass movements.

\section{Biancane}

The term biancane derives from the light colour that the dry clay assumes, also due to salt efflorescences that encrust the outcrops. It refers to roundish hillocks, with a maximum height of about ten meters, with sides more or less dried up with downwards diverging rivulets, very rarely isolated, rather grouped together to form very rough sets. Similar forms have also been indicated with the nickname of elephant's sides. The biancane landscapes are generally characterized by the presence of a dense hydrographic network, controlled by fractures, arranged to form more or less regular grid, isolating small hills, on which erosive processes successively act, rounding it, so originating the so called biancane (Alexander 1982).

The erosive process that shapes such landforms, seems to consist essentially in the removal of the small clayey layers fragments on the outer surface, due to the superficial drying; this material, once fluidized, flows towards the base of the small reliefs, where it is generally arranged in low-steep and coalescent alluvial zones. Currently, the biancane areas are not numerous, since in the last decades - these forms have been dismantled and levelled, in order to make them usable for agricultural purposes (D'Alessandro 2004).

\section{Dolomites}

Dolomites, a mountain chain in the north-east of Italy, exciting for the beautiful landscape, is a resource, especially for tourism and sports since it draws visitors from all over the world both in summer and winter. Due to the mineral composition of the rocks a special visual phenomenon happens every day: the Enrosadira; the Dolomite rocks change colour during the day, from orange to red to purple at dawn and sunset, light yellow at midday and at twilight, becoming a pale white in the moonlight. The Dolomite landscape is characterized by several peaks exceeding 3,000 $\mathrm{m}$ whose rocks and morphology are the result of the geological evolution: tectonic movements, glacial erosion, karst phenomena are easily recognizable and explainable to anyone visiting these amazing places (Panizza 2017). After the Ercinic Orogeny (Carboniferous, about 300 million years ago), an intense volcanic activity determines 
the placement of the ignimbrites/porphyries of the Atesino Volcanic Complex (270-275 million years ago). Subsequently, a vast alluvial plain is formed in an arid and semidesert environment. The sea begins to grow from 250 million years ago, always in an arid environment. In climatic conditions much warmer than the current ones, between 240 and 180 million years ago, a tropical marine environment developed (similar to the current Caribbean one), characterized by seas generally with shallow depths, mainly carbonate sediment. Carbonate platforms broke up, connected to emerged areas or delimited by basins (Bahamian type platforms).

Dolomite, the mineral that gives the name to the Dolomites is the result of changes in the composition of limestone, probably due to the action of warm waters perhaps linked to magmatic activity. In the Middle Triassic (about 230 million years ago) an important volcanic district was set up with the emission of basaltic magmas.

Starting from about 180 million years ago, the sea progressively deepens. The Alps are formed between the Upper Cretaceous and the Oligocene (80 to 30 million years ago). The Dolomites rise between the end of the Oligocene and the Miocene (20 to 5 million years ago). During the last glaciation (Würm), which began 75,000 years ago and ended 10,000 years ago, the Dolomites, in the period of maximum expansion of the glaciers, were covered by ice, except for the highest peaks (Neri et al. 2007). The description of the landscapes units, as well as the landscape type's one, are available on the LandscApp; such further information, about the geological evolution of the sites, are going to be added.

\section{Conclusions}

Some special landscape settings are worthy of appropriate protection, due to scientific and management reasons. The scientific debate provides numerous indications regarding methods and criteria for the census, knowledge, and enhancement of sites of geological interest (geosites). However, there is no sufficient attention on this theme, neither by the territorial managers nor by the public. The roots of such inattention is mostly due to a misunderstanding about what landscape is and what it means. Usually, thematic information reaches only a restricted target audience which is already sensitized; there are consistent brackets of the national population that are not involved at all. In addition to this, in spite of the great variety of information and communications technology channels, we observe that the shared information is characterized by superficiality and fragmentation; the effect is the risk to distort reality into a sort of fiction, to transform science in science fiction. On the other hand, within the scholastic context, environmental issues are left to teachers' initiative and study programs have been reduced. At academic and professional level, environmental problems are divided in single and separate disciplines, thus impoverishing their complexity. The consequences of this are evident in the lack of connections between the academic research world, the professional context and the policy-making institutions, as well as in the low levels of efficacy of the actions for landscape's safeguard and promotion.

In order to guarantee effective information, it is mandatory to provide proper communication of landscape heritage and related rights and responsibilities, to the widest possible audience, with the aim of involving the society into a more effective participatory democracy.

Basing on the results of the previous experimental action in this field, the essential basis are synthesized in the following proposals:

- to work for the collaboration and networking of different stakeholders and places (cinema, theatres, museums, parishes, stadium, etc.), in order to spread sensitization messages, aimed to protecting and enhancing the environment, as well as to preventing risks,

- to figure out new ways of communicating environmental topics,

- to choose, within project's implementation, specific and relevant pilot places, with a representative geographical coverage, in terms of: environmental landscape value; territorial vulnerability; landscape promotion; prevention of geographical and environmental risks; infrastructure sustainability; relevance,

- to act in a multi-scale perspective, in order to transmit clear sensitization messages in schools, but also in other contexts targeting wide and varied audience groups, not considered, to this day, as environmental communication's beneficiaries.

\section{Acknowledgments}

The authors wish to thank Patrick O'Brien for the manuscript revision and to Fabio Baiocco for the LandscApp realization. The authors are grateful to the reviewers for insightful and valuable remarks to the preliminary version of the paper.

\section{Author Contributions}

Conceptualisation: F.R.Lugeri, P.Farabollini; Data curation: F.R.Lugeri, N.Lugeri; Investigation: F.R.Lugeri, P.Farabollini; Methodology: F.R.Lugeri, P.Farabollini, N.Lugeri; Writing - review \& editing: F.R.Lugeri, N.Lugeri.

\section{Funding}

This research received no external funding. 


\section{References}

Alexander D. E., 1982. Difference between calanchi and biancane badlands in Italy. In: R.Bryan, A.Yair (eds), Badland Geomorphology and piping. Geo books, Norwich: 71-88.

Amadio V., 2003. Analisi di Sistemi e Progetti di Paesaggio. Angeli, Milano.

Amadio V., Amadei M., Bagnaia R., Di Bucci D., Laureti L., Lisi A., Lugeri F.R., Lugeri N., 2002. The role of Geomorphology in Landscape Ecology: the physiographic unit Map of Italy, Scale 1: 250,000 ("Carta della Natura" Project). In: R.J.Allison (eds), Applied Geomorphology: Theory and Practice, Wiley: London: 265-282.

APAT, 2003. Carta della natura alla scala 1:250.000: metodologie di realizzazione. Manuali e Linee Guida 17/2003. Roma.

APAT, 2004. Carta della natura alla scala 1:50.000: metodologie di realizzazione. Manuali e Linee Guida 30/2004, Roma.

Bauman Z., 1997. Postmodernity and its discontents. Polity, Cambridge.

Bentivenga M., Fascetti S., 1999. Le aree calanchive della Basilicata: aspetti geomorfologici e geobotanici. Biologi italiani 5: $16-24$

Cayla N., Hobléa F., Reynard E., 2014. New Digital Technologies Applied to the Management of Geoheritage. Geoheritage 6(2): 89-90. DOI: 10.1007/s12371-014-0118-8

Cayla N., Martin S., 2018. Digital geovisualization technologies applied to geoheritage management. In: E.Reynard, J.Brilha (eds), Geoheritage: Assessment, Protection, and Management, Elsevier. DOI: 10.1016/B978-0-12-809531-7.00008-3

Neri C., Gianolla P., Furlanis S., 2007. Note illustrative della Carta geologica d'Italia alla scala 1:50,000, foglio 029, Cortina d'Ampezzo / a cura di - Roma, SystemCart.

Ciaranfi N., Gallicchio S., Girone A., Maiorano P., Marino M., 2010. Proposta di un percorso geologico culturale tra i calanchi del geosito di Montalbano Jonico (Basilicata). Geologia dell'Ambiente, suppl. 2/201: 214-226.

Council of Europe, 2000. European Landscape Convention. European Treaty Series, No. 176; Strasbourg.

D'Alessandro L., 2004. Forme di erosione superficiale: calanchi e biancane. Online: https://www.igmi.org/italia-atlante-dei-tipi-geografici/consulta-latlante - 20.04.2018.

Crutzen P.J., 2006. The "Anthropocene". In: E.Ehlers, T.Krafft (eds), Earth System Science in the Anthropocene. Springer, Berlin, Heidelberg.

Dramis F., Gentili B., Coltorti M., Cherubini C., 1982. Piano di Gestione. Riserva dei Calanchi di Montalbano Provincia di Matera 60. Osservazioni geomorfologiche sui calanchi. Geografia Fisica Dinamica Quaternario 5: 38-45.

Farabollini P., Lugeri F.R., Amadio V., 2014. Geomorpho-Landscapes. Geophysical Research Abstracts, 16: EGU2014-4775-1.

Farabollini P., Miccadei E., 2009. The geomorpho-touristic landscapes of Marche-Abruzzi region: perspective for geo-excursionism between geomorphological emergency, geomorphosites and geoparks. Geoitalia 2009, Rimini, 9-11 Settembre. Epitome 3: 378.

Farabollini P., Scalella G., 2014. Geotouristic routes in Monte Ascensione and badlands district. Memorie Descrittive della Carta geologica d'Italia 102: 57-72.

Festa V., Sabato L., Tropeano M., 2018. 1:5,000 geological map of the Upper Cretaceous intraplatform-basin succession in the "Gravina di Matera" canyon (Apulia Carbonate Platform, Basilicata, southern Italy). Italian Journal of Geosciences 137(1): 3-15. DOI: 10.3301/IJG.2017.12

Forman R., Godron M., 1986. Landscape Ecology. Wiley, New York.
Gambino F., Borghi A., d'Atri A., Gallo L.M., Ghiraldi L., Giardino M., Martire L., Palomba M., Perotti L., Macadam J., 2017. TOURinSTONES: a Free Mobile Application for Promoting Geological Heritage in the City of Torino (NW Italy). Geoheritage. DOI: $10.1007 /$ s12371-017-0277-5.

Giardino M., Mortara G., De Renzo G., 2002. Geosites in the Turin's Province (NW-Italy): scientific researches and exploitation perspectives. In: P.Coratza, M.Marchetti (eds), Proceedings Workshop Geomorphological sites: researches, assessment and improvement.

ISPRA, 2018. Consumo di suolo, dinamiche territoriali e servizi ecosistemici. Rapporti 288/2018.

IYPE [International Year of Planet Earth], 2007. International Year of Planet Earth 2007-2009. Online: www.yearofplanetearth. org/ - 11.12.2017.

Lugeri F.R., Farabollini, P., Amadio V., Greco, R. 2018. Unconventional Approach for Prevention of Environmental and Related Social Risks. A Geoethic Mission. Geosciences 8(2): 54. DOI: 10.3390/geosciences8020054.

Lugeri F.R., Aldighieri B., Testa B., Cardillo A., 2012. WebGIS territoriale: per non perdere contatto con la realtà - webGIS territorial: pour ne pas perdre le contact avec la réalité" in AAVV Geografia sociale e democrazia - La sfide della comunicazione a cura di Claudio Cerreti, Isabelle Dumont. Massimiliano Tabusi, Aracne ed. Roma: 95-104.

McKinster J., Trautmann N., Barnett M., 2013. Teaching Science and Investigating Environmental Issues with Geospatial Technology: Designing Effective Professional Development for Teachers. Springer Science \& Business Media, Berlin: 353.

Naveh Z, Lieberman A.S., 1994. Landscape Ecology Theory and Application. Series on Environmental Management. Springer, New York.

Panizza M., 2017. Nomination of the Dolomites for inscription on the World Natural Heritage List UNESCO. In: M.Soldati, M.Marchetti (eds). Landscapes and Landforms of Italy, Springer, Berlin: 7-20.

Panizza M.,; Piacente S., 2005. Geomorphosites: A bridge between scientific research, cultural integration and artistic suggestion geomorphological sites and geodiversity. Il Quaternario Italian Journal of Quaternary Sciences 18(1): 3-10.

Panizza M., Reynard E., 2005. Géomorphosites: définition, évaluation et cartographie. Géomorphologie: Relief, Processus, Environnement 3: 177-180.

Pica A., Reynard E., Grangier L., Kaiser C., Ghiraldi L., Perotti L., Del Monte M., 2017. GeoGuides, urban geotourism offer powered by mobile application technology. Geoheritage 10(2): 311-326. DOI: 10.1007/s12371-017-0237-0.

Reynard E., Kaiser C., Martin S., Regolini G., 2015. An application for geosciences communication by smartphones and tablets. In: G.Lolino, D.Giordan, C.Marunteanu, B.Christaras, I.Yoshinori, C.Margottini (eds), Engineering Geology for Society and Territory. Volume 8 Preservation of Cultural Heritage, Springer: 265-268.

Reynard E., Giusti C., (2018). The landscape and the cultural value of geoheritage. In: E.Reynard, J.Brilha (eds), Geoheritage: Assessment, Protection, and Management, Elsevier, Amsterdam: 147-165. DOI: 10.1016/B978-0-12-809531-7.00008-3.

Sieber R., 2006. Public Participation Geographic Information Systems: A Literature Review and Framework. Annals of the American Association of Geographers 96: 491-507.

Wimbledon W.A.P., 1996. Geosites - A new conservation initiative. Episodes 19: 87-88.

Zwoliński Zb., Najwer A., Giardino M., 2018. Methods for Assessing Geodiversity. In: E.Reynard, J.Brilha (eds), Geoheritage: Assessment, Protection, and Management, Elsevier, Amsterdam: 27-52. DOI: 10.1016/B978-0-12-809531-7.00002-2. 